\title{
Ultrasonic Effect on Ultrafiltration Properties of Ceramic Membrane
}

\author{
Takao Kokugan, Kaseno, Shiro Fujiwara and Masaru Shimizu
}

Department of Chemical Engineering Tokyo University of Agriculture

and Technology Koganei Tokyo 184

\begin{abstract}
To investigate the effect of ultrasonic irradiation on ultrafiltration (UF) properties, three kinds of solutions : in which a gel layer was easy to form, difficult to form and whose properties were in between, were examined. Ultrasound was irradiated on about $1 / 8$ of the permeation surface of a ceramic membrane. Ultrasonic irradiation affected a gel and a boundary layers. The mass transfer coefficient for UF of ceramic membrane can be correlated to the Sherwood number. The Sherwood number were correlated nearly by Leveque equation without ultrasonic irradiation. But when ultrasound was irradiated, the Sherwood number was larger about by 1.4 times than the one without ultrasonic irradiation. An ultrasonic irradiation had a tendency to decrease the observed rejection slightly by increasing permeation flux whether a gel layer forms on the surface or not.
\end{abstract}

Key words : Ultrasound, Ceramic membrane, Ultrafiltration, Permeation flux, Rejection, Ovalbumin, PVA, Dextran.

\section{Introduction}

Since progress in the technology of processing has been advancing, and nanometer control for porous ceramic materials has become possible, applications for utilizing ceramic membranes, especially in the field of food processing industries, chemical industries and pharmaceutical industries, have been widely adopted. Before the development of ceramic membranes, polymer membranes were used for ultrafiltration (UF). Therefore, the development of ceramic membranes whose characteristics include chemical stability and mechanical durability, is highly expected to improve the material by more precise manufacturing and to open up new fields of applications.

One of the characteristics of UF is the build up of concentration polarization and gel polarization near the surface of the membrane, which causes the permeation flux to decrease. To increase the permeation flux, feed flow rate is usually increased. This condition slows down formation of gel or polarization of concentration near the surface. Other ways of enhancing the permeation characteristic of ceramic membranes are the application of vibration and sponge ball. Yukawa et al. ${ }^{1 \sim 4)}$ concluded through quantitative analysis that decrease of permeation flux can be prevented by the application of an electrical 


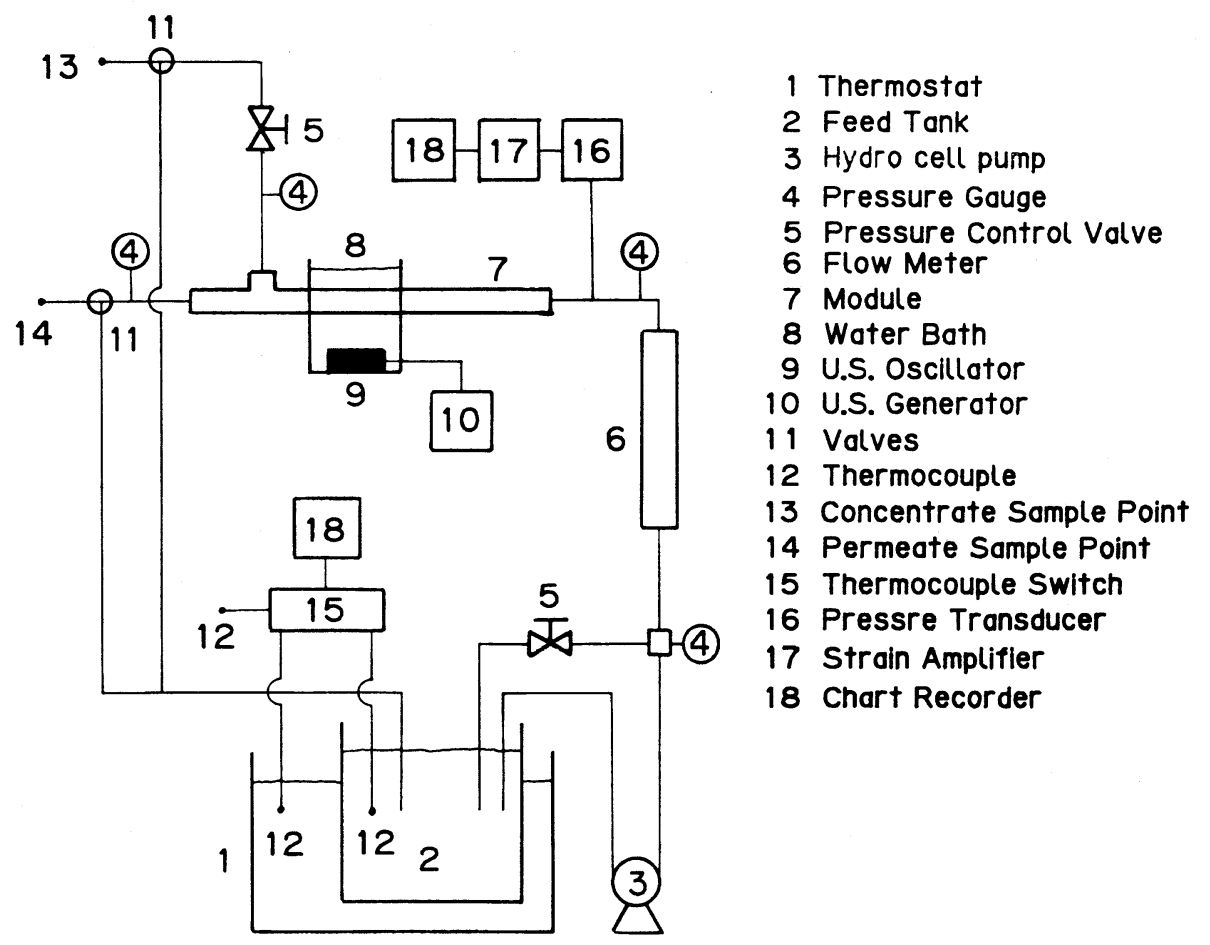

Fig. 1. Schematic diagram of experimental apparatus

field to UF in colloidal solution. This application of an electrical field to the solution causes the colloid near the membrane surface to move to the bulk of the liquid by electrophoresis. Furthermore, they found that it was very important that UF for colloidal solution with isoelectric point be done at an appropriate $\mathrm{pH}$, and that the reflection coefficient of the colloidal solution was strongly influenced by the Reynolds number, the strength of the electrical field and concentration of the diffusing particles. Kimura et al. ${ }^{5)}$ examined the effect of an electrical field on UF. They concluded that the UF for a charged protein solution whose electrical conduction is low can be treated with higher efficiency by applying an electrical field. In order to decrease gel formation, Imasaka et al. ${ }^{6}$ reported that when gas was supplied from the bottom of the membrane module, the permeation characteristic of the UF membrane can be enhanced.

The effect of ultrasonic vibration on dis- $^{-}$ persion, coagulation, degassing, dissolving, and chemical reaction promotion have been known. Sakakibara et al. ${ }^{7)}$ applied ultrasound on a sphere in electrolyte solution and measured the average of the mass transfer coefficient on the sphere surface by using the rate determining process of diffusion in the electrode reaction. By supplying $25 \mathrm{kHz}$ of ultrasound to an extraction sample, Hoshino et al. ${ }^{8)}$ developed liquid-liquid extraction equipment and examined its characteristic and efficiency. Zanwar et al. ${ }^{9)}$ applied ultrasound to a fixed bed reactor, examined its promotion effect on its mass transfer co- $^{-}$ efficient, and proposed a correlation for the 


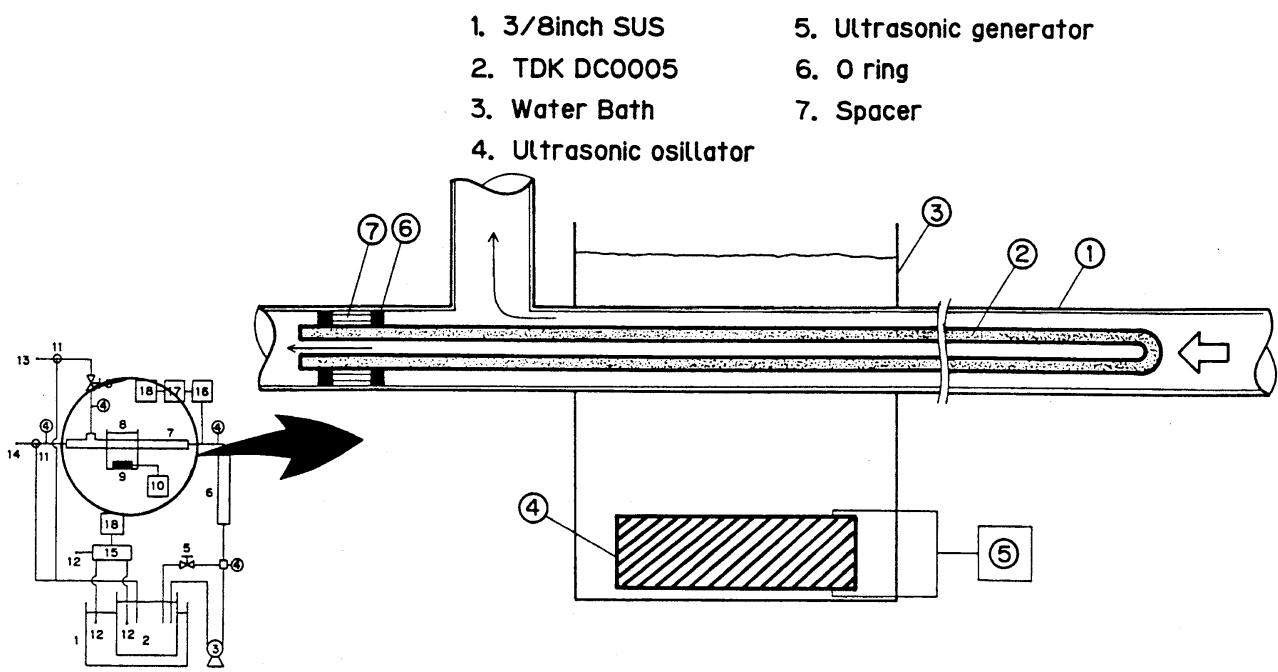

Fig. 2. Detail of main assembly

Sherwood number. However, the influence of ultrasound on the characteristic of UF has hardly been reported ${ }^{10)}$.

The aim of present study is to investigate the effect of ultrasonic irradiation on the UF characteristics of ceramic membrane and to discuss the fouling effect of UF, which is an important problem for the UF of ceramic membranes. Such information may be useful when ultrasonic irradiation on UF is used in industry.

\section{Experimental Apparatus and Method}

A schematic diagram of the experimental apparatus is shown in Fig. 1. Apparatus of ultrafiltration(UF) was an external pressurized single tube module. It was operated with a total circulation flow system. The sample solutions, which were in a constant temperature bath of $25 \pm 1^{\circ} \mathrm{C}$, were supplied to the module by hydro-cell pump. The pressure difference across the membrane was measured by pressure transducer and changed from 1 to $7 \mathrm{kgf} / \mathrm{cm}^{2}$. The feed flow rates were changed from 0.5 to $4.0 \mathrm{l} / \mathrm{min}$.

Details of the main part of the apparatus are shown in Fig. 2. Ceramic membranes used in the present experiment were Dynaceram DC 0005 membranes which were prepared by TDK Co. Ltd. The membranes

were closed at one end and were located inside a $3 / 8$ inch stainless tube. The average pore diameters of the support layer and the skin layer of the ceramic membranes are $0.5 \mu \mathrm{m}$ and $0.05 \mu \mathrm{m}$ respectively. The outand in-diameters of the ceramic membrane are 5 and $3 \mathrm{~mm}$, respectively. The length of the ceramic membrane was $550 \mathrm{~mm}$. A constant temperature bath $\left(25 \pm 1^{\circ} \mathrm{C}\right)$ was located in the middle of the membrane module. An immersion type ultrasonic oscillator was set up inside the bath. The oscillators were disks of diameter $60-70 \mathrm{~mm}$, and were fixed at $20 \mathrm{~mm}$ below the stainless tube. Ultrasonic oscillators were prepared by Ultrasonic Industry Co.Ltd. This oscillator can be adjusted to deliver maximum $150 \mathrm{~W}$ power, and its frequency can be adjusted from 25 
Table 1 Physical Properties of the Solutions (298K)

\begin{tabular}{lcccc}
\hline & $\begin{array}{c}\text { molecular weight } \\
(-)\end{array}$ & $\begin{array}{c}\text { concentration } \\
(\mathrm{ppm})\end{array}$ & $\begin{array}{c}\text { viscosity } \\
\times 10^{3}(\mathrm{sp} \cdot \mathrm{a})\end{array}$ & $\begin{array}{c}\text { diffusion coefficient } \\
\times 10^{12}\left(\mathrm{~m}^{2} / \mathrm{s}\right)\end{array}$ \\
\hline \multirow{2}{*}{ Ovalbumin } & 46,000 & 1000 & 0.918 & 77.9 \\
& & 2000 & 0.930 & 77.7 \\
PVA-500 & 3000 & 0.942 & 77.5 \\
Dextran 100-200 & $100,000-200,000$ & 1000 & 2.40 & 40.7 \\
\hline
\end{tabular}

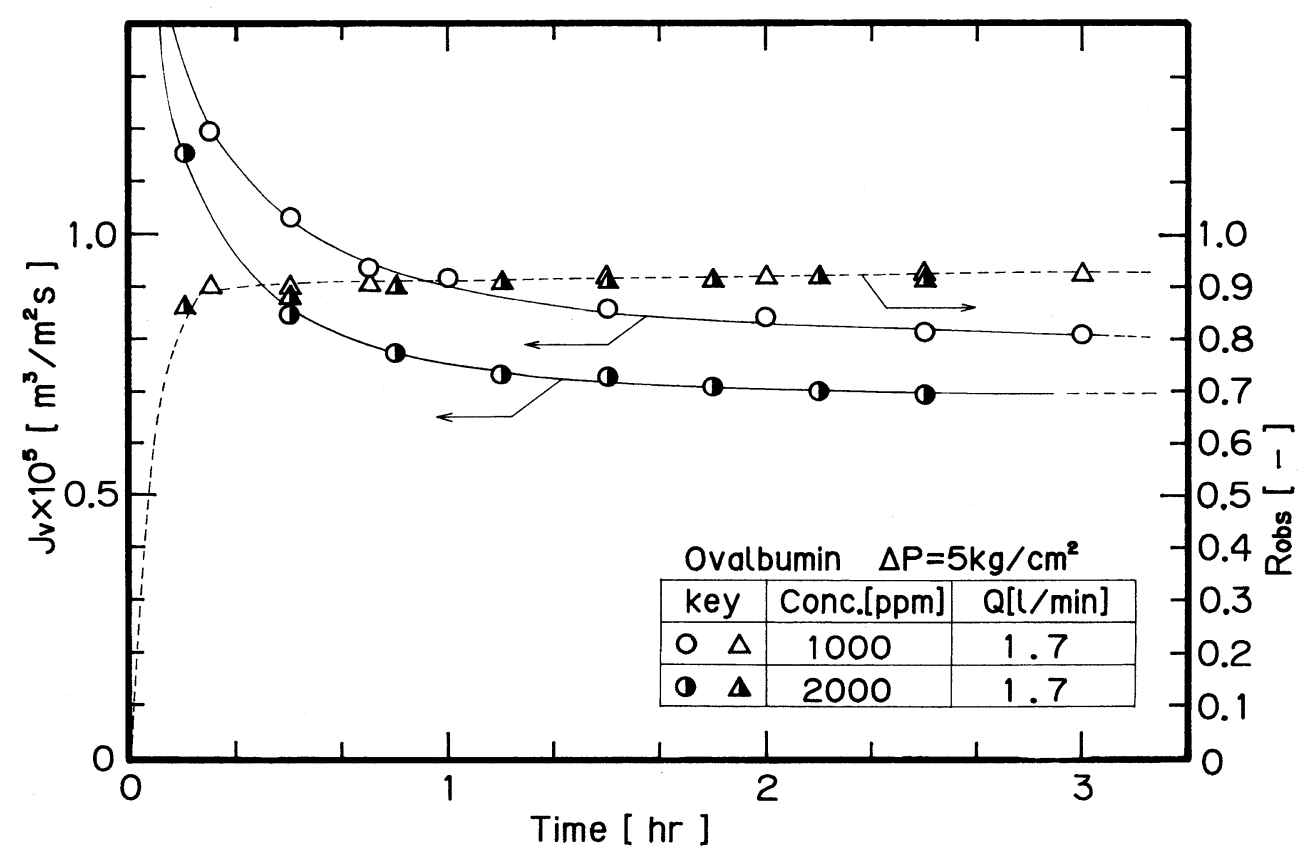

Fig. 3. Change in permeation flux and observed rejection with operating time.

$\mathrm{kHz}$ to $1.2 \mathrm{MHz}$. In the present experiment, disk type barium-titan vibrators were used. The output of this vibrator can be adjusted to deliver power from 70 to $100 \mathrm{~W}$ and frequency from $200 \mathrm{kHz}$ to $400 \mathrm{kHz}$. The ultrasounds were irradiated on about $1 / 8$ of permeation surface of the ceramic membrane.

Three kinds of polymer solutions: ovalbumin solution which can easily form a gel layer, dextran solution which can barely form a gel layer and PVA solution whose properties are in between those of ovalbumin and dextran were used in the present experiment. The concentration of these polymer solutions were adjusted between 1,000 and 4,000 ppm. These samples were analyzed by spectroscopic meter. The wave lengths for ovalbumin and dextran were $280 \mathrm{~nm}$ and for PVA solution it was $190 \mathrm{~nm}$. Physical properties of these solutions are shown in Table 1 


\section{Results and Discussion}

\section{1 Time history of permeation flux and} observed rejection for the ceramic membrane

In order to investigate the initial interaction between ceramic membrane and solute, the behaviors of permeation flux $\left(J_{V}\right)$ and the observed rejection $\left(R_{o b s}\right)$ for ovalbumin solution are shown in Fig. 3 as a function of time. The permeation flux of ovalbumin decreased rapidly for 1 hour after starting the experiment. This trend did not change, regardless of changing the concentration of solution. In addition, the time to reach a steady state did not change, regardless of changing feed flow rate in the range of the present work. But the time to reach the steady state depended on the kind of solution. In the cases of dextran and PVA solutions which develop a gel layer with difficulty, it took 2-3 hours to reach steady state.

On the other hand, for observed rejection it took 20 minutes to steady state for ovalbumin solution and about 50 minutes for dextran and PVA solutions. To investigate the effect of ultrasonic irradiation on UF properties, the data under steady state were used after here.

\section{2 The effect of ultrasonic irradiation} on permeation flux and observed Rejection

The effect of ultrasound on UF can be explained with the following regions.

(a) Boundary layer.

(b) Gel layer.

(c) Pore inside membrane.

(d) The body of the membrane.

Fig. 4 shows the overall effect of ultrasound on the permeation fluxes $\left(J_{V}\right)$ and observed rejections $\left(\mathrm{R}_{o b s}\right)$ for pure water and ovalbumin solution. Three different concen-

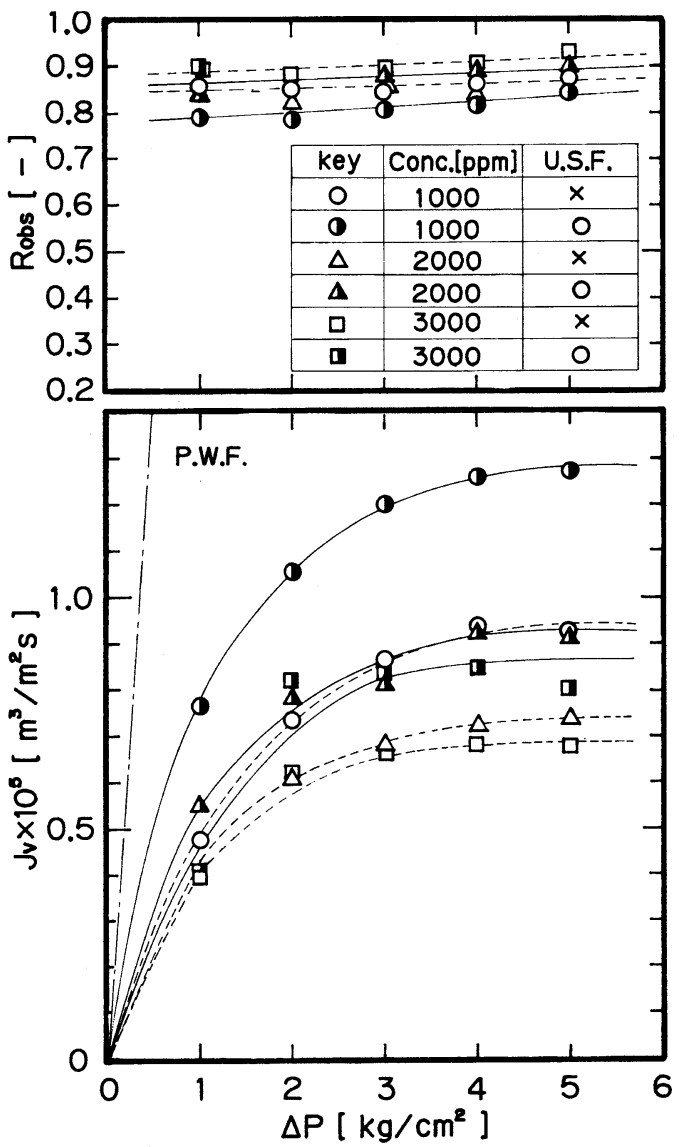

Fig. 4. Relationship between permeation flux and observed rejection and operation pressure for ovalbumin solution

trations were prepared for the ovalbumin solution. In order to avoid increase in temperature caused by the ultrasonic irradiation, the water bath was cooled to constant temperature at $25 \pm 1^{\circ} \mathrm{C}$. As a result, the ultrasonic effect on permeation flux for pure water (P.W.F : one dotted line in the figure) was not observed. Therefore, it could be determined that ultrasonic irradiation did not affect the UF properties of the ceramic membrane itself. For the ovalbumin solution there are critical permeation fluxes, where $\mathrm{J}_{V}$ depends barely on pressure difference 


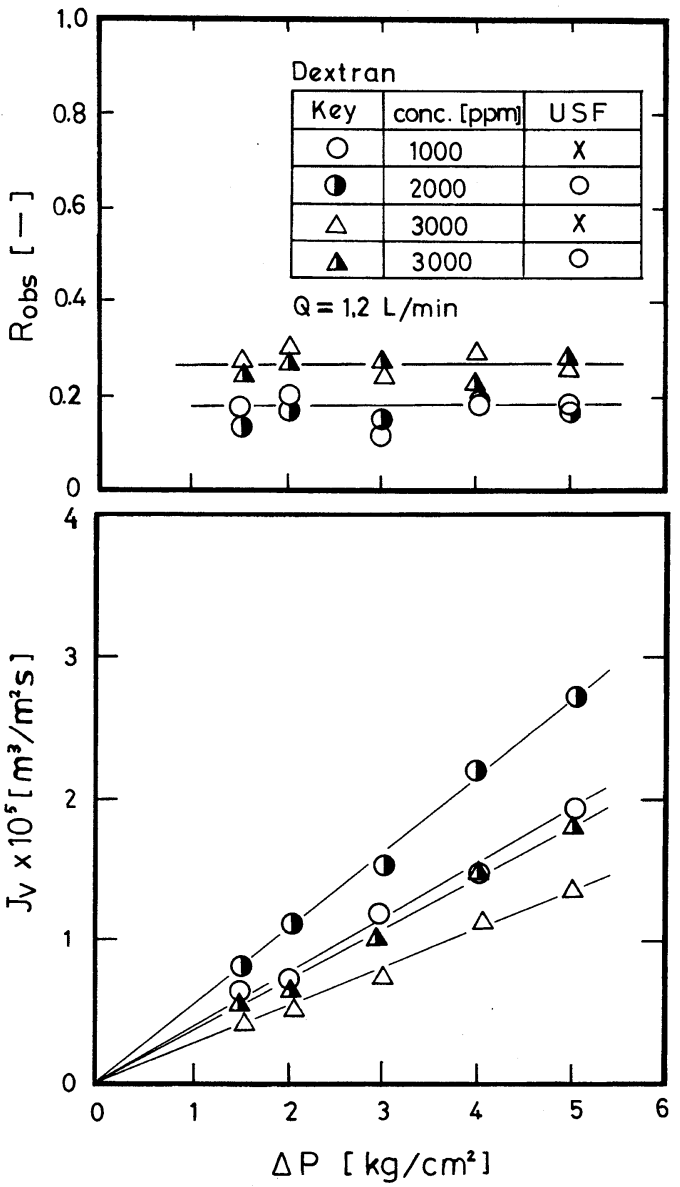

Fig. 5. Relationship between permeation flux and observed rejection and operation pressure for dextran solution

$(\Delta \mathrm{P})$ across membrane, whether ultrasonic irradiation is or not. The $J_{V}$ is strongly affected by ultrasonic irradiation. The effect of ultrasonic irradiation on $\mathrm{J}_{V}$ was larger when the concentration of ovalbumin solution was smaller. On the other hand, the $R_{o b s}$ is high and slightly decreased by ultrasonic irradiation as a portion to increase $\mathrm{J}_{V}$.

For dextran solution, the effects of operation pressure $(\Delta P)$ on permeation flux $\left(J_{V}\right)$ and observed rejection $\left(R_{o b s}\right)$ are shown in

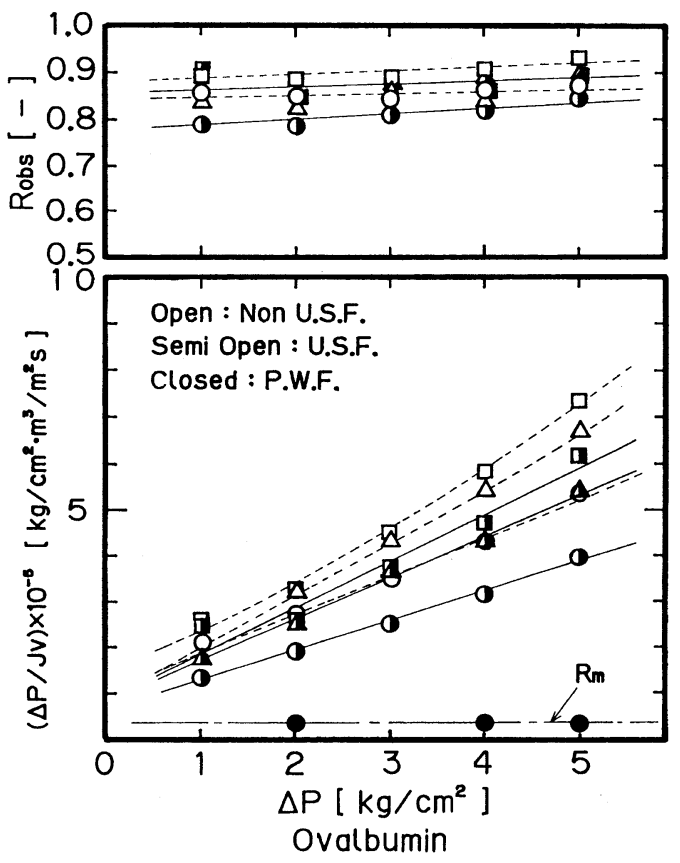

Fig. 6. Relationship between permeation resistance and operation pressure (All keys are the same as in Fig. 4)

Fig. 5. The $J_{V}$ is larger by several times than one for ovalbumin solution. The $\mathrm{J}_{V}$ increases with $\Delta \mathrm{P}$ and there is no critical flux for the dextran solution in the present ex$^{-}$ perimental conditions. The flux increases by ultrasonic irradiation by $30-40 \%$. On the other hand the observed rejection is very low and slightly decreased by ultrasonic irradiation as a portion to increase $J_{V}$. The permeation behaviors for the PVA solution are nearly same to those for dextran solution. It may be considered that a gel polarization model is fitted for ovalbumin solution from critical permeation flux and high rejection while for dextran and PVA solutions concentration polarization model is suitable because critical flux is not and the rejection is low.

For the ovalbumin solution, above critical 
(a)

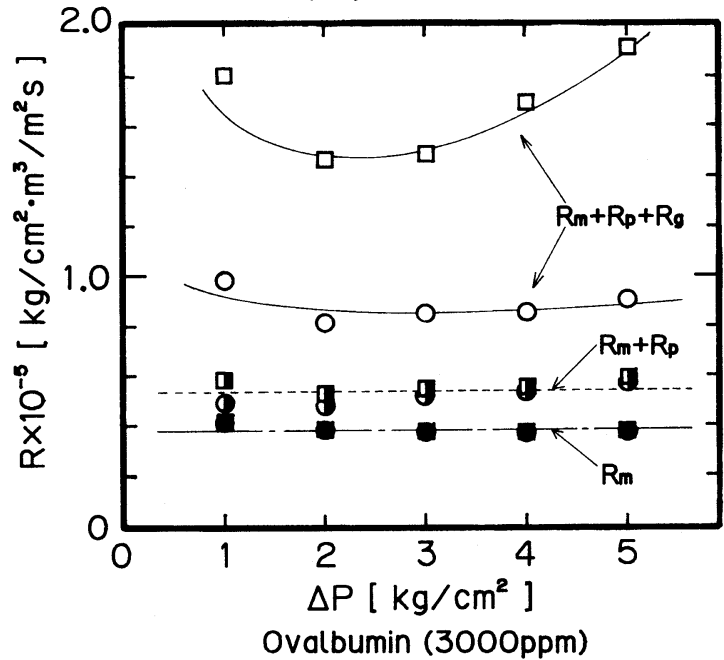

(b)

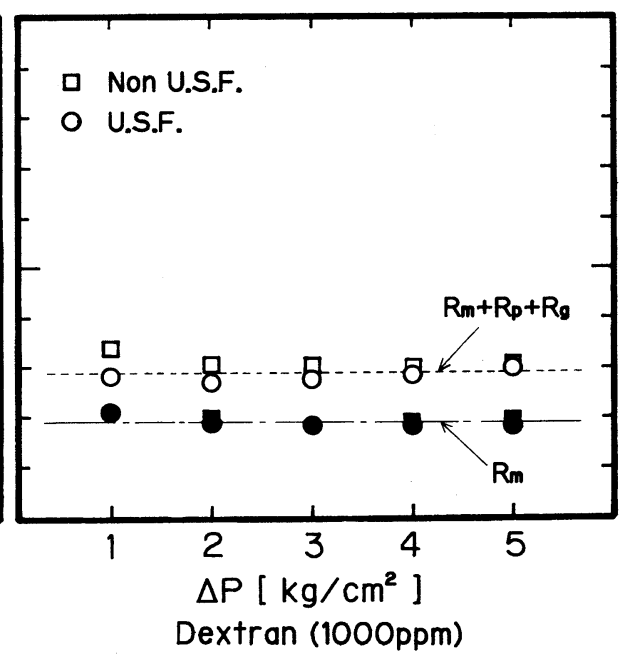

Fig. 7. Comparison of permeation resistance for ovalbumin solution (a) with that for dextran solution (b)

permeation flux in the figure 4 a gel layer forms on the surface of ceramic membrane, no matter how dilute the concentrations are. The gel layer can be more easily taken off from surface of ceramic membrane by ultrasonic irradiation when the layer is thinner.

\section{3 Effect of ultrasonic irradiation on} permeation resistance.

Fig. 6 shows the result of the permeation resistance of ovalbumin with and without ultrasounds. In this figure, the closed circle symbols (O) are the intrinsic membrane $\mathrm{re}^{-}$ sistance and they did not change whether ultrasound was applied or not. The other symbols are the same as those in Fig. 4. Permeation flux $J_{V}$ can be expressed with the term of resistance of $R_{T}$ as in Eq. (1).

$$
\begin{aligned}
& \mathrm{J}_{V}=\Delta \mathrm{P} / \mu \mathrm{R}_{T}{ }_{T}=\Delta \mathrm{P} / \mathrm{R}_{T} \\
& \mathrm{R}_{T}=\Delta \mathrm{P} / \mathrm{J}_{V}
\end{aligned}
$$

When $\Delta \mathrm{P}$ is $3 \mathrm{~kg} / \mathrm{cm}^{2}$, the total permeation resistance $\left(R_{T}\right)$ is about ten times higher than the original resistance of the ceramic membrane. But when ultrasound is applied to the membrane, permeation resistance was reduced by about $20-30$ percent of $R_{T}$. The rate of permeation recovery by ultrasonic irradiation did not change even though $\triangle P$ changed. To investigate the effect more in detail, the local permeation resistance was studied.

$$
\mathrm{R}_{T}=\mathrm{R}_{m}+\mathrm{R}_{p}+\mathrm{R}_{g}+\mathrm{R}_{b}
$$

In order to investigate the effect of ultrasound on each local permeation resistance, the following experiments were conducted with and without ultrasounds.

(a) After the permeation experiments with the solution were over, the solution was $\mathrm{re}^{-}$ placed by distilled water, and the permeation experiments were repeated under the same conditions.

(b) After the experiment (a), the ceramic 
membrane was slowly taken out from the module, and was brushed softly with a sponge to remove the gel layer deposited on the membrane surface. After washing it with water, the membrane was inserted back into the module. The experiments were $\mathrm{re}^{-}$ peated with pure water.

(c) Before the permeation experiments in the solution, the intrinsic permeation resistances of the membrane were measured with pure water.

From experiment (a), total permeation resistance without boundary layer resistance $\left(R_{b}\right)$ can be obtained as follows Eq. (4).

$$
\mathrm{R}_{1}=\mathrm{R}_{m}+\mathrm{R}_{p}+\mathrm{R}_{g}
$$

From the experiment (b), total permeation resistance without gel layer resistance $\left(R_{g}\right)$ can be obtained by Eq. (5).

$$
\mathrm{R}_{2}=\mathrm{R}_{m}+\mathrm{R}_{p}
$$

And from the experiment (c) the initial resistance of the ceramic membrane $R_{m}$ was obtained. From all of these experiments, $\mathrm{R}_{m}, \mathrm{R}_{p}$, and $\mathrm{R}_{g}$ can be obtained individually. The results for ovalbumin and dextran are shown in Figs. 7 a \& $7 \mathrm{~b}$ respectively. In these figures, the three kinds of squares $(\square$,

$\square, \square)$ are the symbols for the experiments without ultrasound, and the three kinds of circle $(\bigcirc,(1)$ ) are the symbols for permeation resistance with ultrasound. From the figure, the gel layer of ovalbumin (Fig. 7a) was easily removed with the help of ultrasound, but this effect was not valid for dextran solution, for which it is difficult to form a gel layer (Fig. 7b). For the dextran solution, the results for experiment (b) were nearly same as the results for experiment (a) whether ultrasound was irradiated or not. Then the results of the dextran solutions for experiment (b) were omitted from Fig. 6 b. From the experiment (c), the effect of ultrasonic irradiation on the intrinsic membrane resistance can not be detected. From the experiments (b) and (c), The influences of ultrasound on permeation resistance of in the pore $\left(R_{p}\right)$ for the two solutions were not observed. When distilled water was used to deplenish the boundary layer, the ultrasonic effect worked only on the gel layer if gel could be formed.

Nabetani et al. carried out UF experiments for ovalbumin solution and they reported that the experimental data were in conflict with three conventional models: gel polarization, osmotic pressure and resistance in series models. Then they presented a new model: osmotic pressure and resistance due to solute adsorption ${ }^{11}$. It is sure that the osmotic pressure of ovalbumin solution is very higher than the value calculated from van't Hoff equation, especially at high concentration. It could be plenty considered that the concentration on the membrane surface grew up due to concentration polarization in the UF, then osmotic pressure resisted to permeation. But in the present conditions, it is natural to consider that a gel layer exists on the ceramic membrane surface for ovalbumin solution because the permeation flux rose up by brushing the membrane surface with a sponge.

\section{4 Effect of ultrasonic irradiation on mass transfer coefficient of UF.}

To study the effect of ultrasonic irradiation on the boundary layer, the concentrations of feed solution were variously changed. The critical permeation flux can be given by the gel polarization model with Eq. (6). 


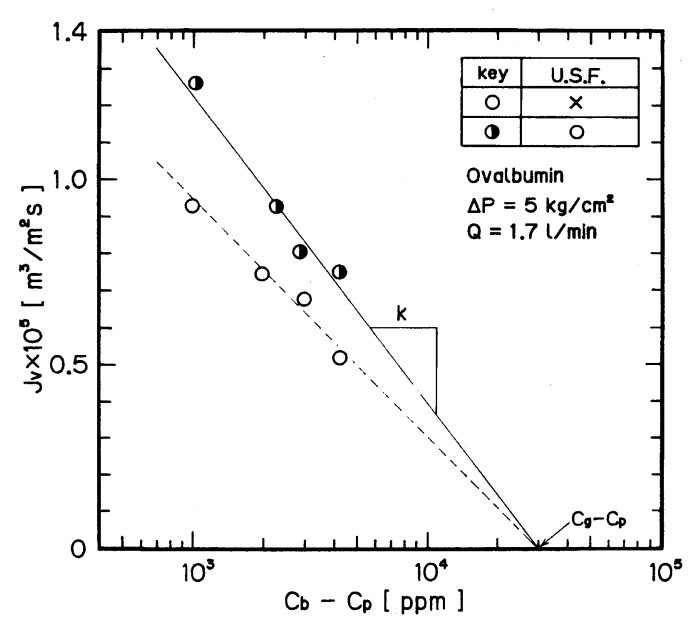

Fig. 8. Relationship of permeation flux and feed concentration for ovalbumin solution

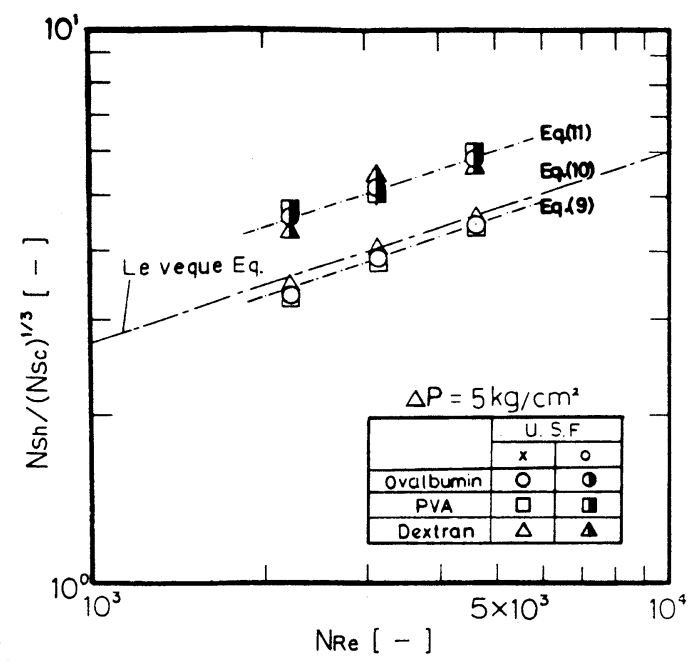

Fig. 10. Correlation of Sherwood number to Reynolds and Schmidt numbers

$$
\begin{aligned}
& \mathrm{J}_{V}=\mathrm{k} \ln \left(\mathrm{C}_{g}-\mathrm{C}_{p}\right) /\left(\mathrm{C}_{b}-\mathrm{C}_{p}\right) \\
& \text { where } \mathrm{k}=\mathrm{D} / \delta
\end{aligned}
$$

Fig. 8. shows the relationship between the permeation flux $\left(J_{V}\right)$ and the concentration of the feed solution $\left(\mathrm{C}_{b}\right)$, with and without ultrasonic irradiations for ovalbumin solu-

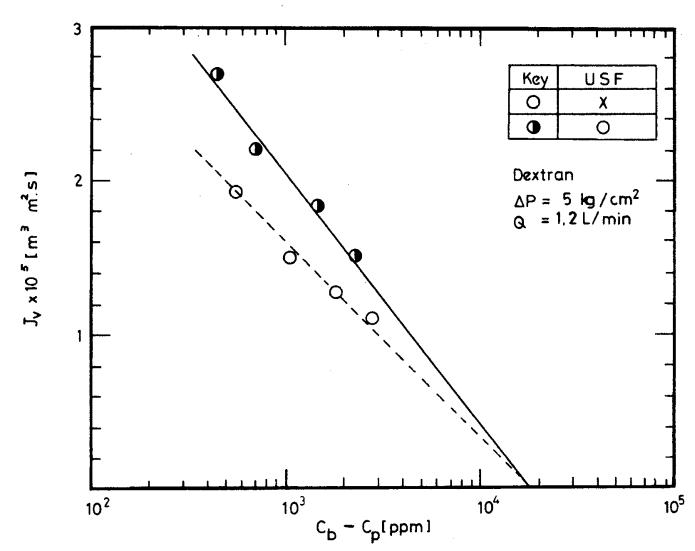

Fig. 9. Relationship of permeation flux and feed concentration for dextran solution

tions. The gradient of the permeation flux with the ultrasonic irradiation was about 1.4 times greater than the one without the ultrasonic irradiation. However, the concentration differences $\left(\mathrm{C}_{b}-\mathrm{C}_{p}\right)$ for the two cases could be extrapolated to the same point where $\mathrm{J}_{V}$ is equal to 0 . And at the point, $\mathrm{C}_{b}$ can be equal to gel layer concentration $\mathrm{C}_{g}$. It was found that the gel concentrations did not change whether ultrasound was irradiated or not. The relationship between flux and feed concentration for dextran solution is shown in Fig. 9. As the same case of ovalbumin solution, the gradient of the permeation flux with the ultrasonic irradiation was about 1.4 times greater than the one without the ultrasonic irradiation. But the slope is larger than the one for ovalbumin solution. The concentration differences $\left(\mathrm{C}_{b}-\mathrm{C}_{p}\right)$ for the two cases could be extrapolated to the same point where $J_{V}$ is equal to 0 . But it is smaller than the one for ovalbumin solution. Those relations were also valid for the PVA solution.

From those informations, it can be inferred that if ultrasound was applied to the UF 


\begin{tabular}{|c|c|c|}
\hline \multicolumn{3}{|c|}{ Symbols } \\
\hline $\mathrm{C}$ & : concentration & {$\left[\mathrm{kg} / \mathrm{m}^{3}\right]$} \\
\hline $\mathrm{D}$ & : diffusion coefficient & {$\left[\mathrm{m}^{2} / \mathrm{s}\right]$} \\
\hline$d$ & : equivalent diameter & {$[\mathrm{m}]$} \\
\hline $\mathrm{J}_{v}$ & : volume flux & {$\left[\mathrm{m}^{3} / \mathrm{m}^{2} \cdot \mathrm{s}\right]$} \\
\hline $\mathrm{k}$ & : mass transfer coefficient & defined \\
\hline & by Eq.(3) & {$[\mathrm{m} / \mathrm{s}]$} \\
\hline 1 & : membrane length & {$[\mathrm{m}]$} \\
\hline $\mathrm{N}_{R e}$ & : Reynolds number $=\rho \mathrm{dv} / \mu$ & {$[-]$} \\
\hline $\mathrm{N}_{s c}$ & : Schmidt number $=\mu / \mathrm{D} \rho$ & {$[-]$} \\
\hline $\mathrm{N}_{s h}$ & : Sherwood number $=\mathrm{kd} / \mathrm{D}$ & {$[-]$} \\
\hline Q & : flow rate & {$\left[\mathrm{m}^{3} / \mathrm{s}\right]$} \\
\hline $\mathrm{R}_{o b s}$ & : observed Rejection $=1-\mathrm{C}_{p}$ & {$[-]$} \\
\hline $\mathrm{R}$ & : permeate resistance $[\mathrm{Kg} /$ & $\left./ \mathrm{cm}^{2} \cdot \mathrm{s} / \mathrm{m}\right]$ \\
\hline $\mathrm{v}$ & : liner flow rate & {$[\mathrm{m} / \mathrm{s}]$} \\
\hline$\delta$ & : boundary layer thickness & {$[\mathrm{m}]$} \\
\hline$\Delta \mathrm{P}$ & : pressure difference cross & \\
\hline & membrane & {$\left[\mathrm{Kg} / \mathrm{cm}^{2}\right]$} \\
\hline$\mu$ & : viscosity of solution & {$[\mathrm{Pa} \cdot \mathrm{s}]$} \\
\hline & : density of solution & {$\left[\mathrm{kg} / \mathrm{m}^{3}\right]$} \\
\hline$(\mathrm{Su}$ & script) & \\
\hline$b: b$ & oundary, bulk & \\
\hline $\mathrm{g}:$ & & \\
\hline $\mathrm{m}:$ & nembrane & \\
\hline & rmeate, pore & \\
\hline $\mathrm{T}:$ & & \\
\hline
\end{tabular}

membrane, the mass transfer coefficient $(\mathrm{k})$ would become greater by 1.4 times than the one without ultrasonic irradiation, whether the gel layers were formed or not on the surface of a ceramic membrane. In order to $\mathrm{ex}^{-}$ amine the correlation of the mass transfer for three types of the solution, dimensionless groups were analyzed by Eq. (8).

$$
\mathrm{N}_{S h}=\mathrm{c}\left(\mathrm{N}_{R e}\right)^{m}\left(\mathrm{~N}_{S c}\right)^{n}(\mathrm{~d} / \mathrm{l})^{q}
$$

Fig. 10. shows the correlations for the ovalbumin, PVA, and dextran solutions. If ultrasound was not applied, the correlation for the three kinds of solution was repre- sented by Eq. (9).

$$
\mathrm{N}_{S h}=1.58\left\{\mathrm{~N}_{R e} \mathrm{~N}_{S c}(\mathrm{~d} / \mathrm{l})\right\}^{1 / 3}
$$

The values obtained from Eq. (9) were sightly smaller than the one obtained from Leveque Eq. (10) which correlated for laminar flow.

$$
\mathrm{N}_{S h}=1.62\left\{\mathrm{~N}_{R e} \mathrm{~N}_{S c}(\mathrm{~d} / \mathrm{l})\right\}^{1 / 3}
$$

When ultrasound was applied, the value of the Sherwood number for the three kinds of solution were 1.4 times higher than the one without ultrasonic irradiation, and the correlation can be represent by Eq. (11).

$$
\mathrm{N}_{S h}=2.21\left\{\mathrm{~N}_{R e} \mathrm{~N}_{S c}(\mathrm{~d} / \mathrm{l})\right\}^{1 / 3}
$$

It is not clear from the present experiments whether the diffusion coefficient was increased or the boundary layer thickness was decreased by the ultrasonic irradiation, but it was confirmed that the application of $\mathrm{ul}^{-}$ trasonic irradiation can help to increase the mass transfer coefficient, and the permeation flux increases by 1.4 times in present conditions than the one without ultrasonic irradiation.

\section{Conclusion}

The effects of the ultrasonic irradiation on the ultrafiltration using ceramic membrane were studied for three different types of solutions : in which a gel layer was easy to form, was difficult to form and a solution whose properties are in between those two solutions. About $1 / 8$ of the surface of the ceramic membrane was exposed to ultrasound. The following results were obtained for the cases with and without ultrasonic irradiations.

1. Ultrasonic irradiation decreased the 
permeation resistances caused by a gel and a boundary layers. But it could not remove a fouling that occurred inside the pore in the membrane.

2. The mass transfer coefficient of the three types of solution used in the present experiments can be correlated to the $\mathrm{Lev}^{-}$ eque type equation, whether ultrasound is irradiated or not. When ultrasound was applied, the value of the mass transfer coefficient was about 1.4 times higher than the one without ultrasonic irradiation. It was not concerned with whether the solutions were easy to form a gel layer or not.

3. An ultrasonic irradiation had a tendency to decrease the observed rejection slightly by increasing permeation flux whether a gel layer forms on the surface or not.

\section{References}

1) H. Yukawa, K. Kobayashi : Kagaku Kogaku
Ronbunshu, 15, 31 (1989)

2) H. Yukawa, H. Kobuchi and K. Kobayashi : Kagaku Kogaku Ronbunshu, 6, 288 (1980)

3) H. Yukawa, K. Simura, A. Suda and A. Maniwa: J. Chem. Eng. Japan, 16, 246 (1983)

4) H. Yukawa, K. Shimura, A. Suda and A. Maniwa: J. Chem. Eng. Japan, 16, 305 (1983)

5) S. Kimura, T. Nomura : Membrane, 1, 245 (1982)

6) T. Imasaka, N. Kanekuni, N. Yajima, and T. Yoshino : Kagaku Kogaku Ronbunshu, 15, 306 (1989)

7) M. Sakakibara, H. Tatuda and K. Endo : $K a^{-}$ gaku Kogaku Ronbunshu, 9, 336 (1983)

8) T. Hoshino, M. Utiyama, and H. Yukawa : Kagaku Kogaku Ronbunshu, 10, 351 (1984)

9) S. S. Zanwar and V. G. Pangarkar : Chem. Eng. Comm., 68, 133 (1988)

10) S. Fujiwara, Y. Takagi, and T. Kokugan : Kagaku Kogaku Sympo. series, 21, 55 (1989)

11) H. Nabetani, M. Nakajima, A. Watanabe, S. Nakao and S. Kimura : AIChE Journal 36, 907 (1990)

（受付 1995 年 2 月 9 日） 